\title{
THE NATURE AND ORIGIN OF LATERAL COMPOSITION MODULATIONS IN SHORT-PERIOD STRAINED-LAYER SUPERLATTICES
}

\begin{abstract}
A.G: NORMAN *, S.P. AHRENKIEL *, H.R. MOUTINHO *, C. BALLIF *, M.M. ALJASSIM *, A. MASCARENHAS *, D.M. FOLLSTAEDT **, S.R. LEE **, J.L. RENO**, E.D. JONES **, J. MURECKI-MULUNCHICK ***, AND R.D. TWESTEN ****

* National Renewable Energy Laboratory, 1617 Cole Boulevard, Golden, CO 80401, andrew_norman@nrel.gov

**Sandia National Laboratories, Albuquerque, NM

***Department of Materials Science and Engineering, University of Michigan, Ann Arbor, MI

*****Center for Microanalysis of Materials, University of Illinois, Urbana, $\Pi$
\end{abstract}

\section{ABSTRACT}

The nature and origin of lateral composition modulations in (AlAs) ${ }_{m}(\operatorname{In} A s)_{n}$ SPSs grown by MBE on InP substrates have been investigated by XRD, AFM, and TEM. Strong.modulations were observed for growth temperatures between $\approx 540$ and $560^{\circ} \mathrm{C}$ : The maximum strength of modulations was found for SPS samples with InAs mole fraction $x(=n /(n+m))$ close to $\approx 0.50$ and when $\mathrm{n} \approx \mathrm{m} \approx 2$. The modulations were suppressed at both high and low values of $\mathrm{x}$. For $\mathrm{x}>$ 0.52 (global compression) the modulations were along the $<100>$ directions in the (001) growth plane. For $\mathrm{x}<0.52$ (global tension) the modulations were along the two $<310>$ directions rotated $\approx \pm 27^{\circ}$ from [110] in the growth plane. The remarkably constant wavelength of the modulations, between $\approx 20-30 \mathrm{~nm}$, and the different modulation directions observed, suggest that the origin of the modulations is due to surface roughening associated with the high misfit between the individual SPS layers and the InP substrate. Highly uniform unidirectional modulations have been grown, by control of the InAs mole fraction and growth on suitably offcut substrates, which show great promise for application in device structures.

\section{INTRODUCTION}

Lateral superlattices and quantum wire arrays are of interest for application in a variety of novel device structures with potentially improved performance such as quantum wire lasers, lateral superlattice solar cells and polarized light emitters and detectors. One of the most promising ways of realizing these structures is through strain-related self-organization phenomena, e.g. morphological and compositional instabilities, during the growth of strainedlayer superlattices (SLSs). These instabilities can lead to the formation of lateral modulations in SLSs in several different ways as shown in Fig. 1. The instability could take the form of purely an antiphase modulation in the thickness of binary SLS layers (Fig. 1(a)) leading to apparent lateral compositional modulations. Alternatively, if the SLS layers are alloy layers, for example due to vertical intermixing of binary layers, the instability could be purely compositional in nature (Fig. 1(b)) resulting in lateral compositional modulations. Another possibility is that lateral compositional modulation in alloy SLS layers could occur coupled to a morphological instability, e.g. antiphase variation in layer thickness, as shown in Fig. 1(c). An early report of instabilities occurring during the growth of SLSs was by Blakeslee et al. [1], who observed morphological and possibly compositional instabilities during the metal organic vapor phase epitaxy (MOVPE) growth of GaAs $\mathrm{P}_{1-y} / \mathrm{GaAs}$ SLSs on GaAs. Cheng et al. $[2,3]$ discovered the spontaneous formation of lateral quantum wells and superlattices during the molecular beam epitaxy (MBE) growth of strain-balanced vertical short-period strained-layer superlattices (SPSs) 


\section{DISCLAIMER}

This report was prepared as an account of work sponsored by an agency of the United States Government. Neither the United States Government nor any agency thereof, nor any of their employees, make any warranty, express or implied, or assumes any legal liability or responsibility for the accuracy, completeness, or usefulness of any information, apparatus, product, or process disclosed, or represents that its use would not infringe privately owned rights. Reference herein to any specific commercial product, process, or service by trade name, trademark, manufacturer, or otherwise does not necessarily constitute or imply its endorsement, recommendation, or favoring by the United States Government or any agency thereof. The views and opinions of authors expressed herein do not necessarily state or reflect those of the United States Government or any agency thereof. 


\section{DISCLAIMER}

Portions of this document may be illegible in electronic image products. Images are produced from the best available original 'document. 
(a)

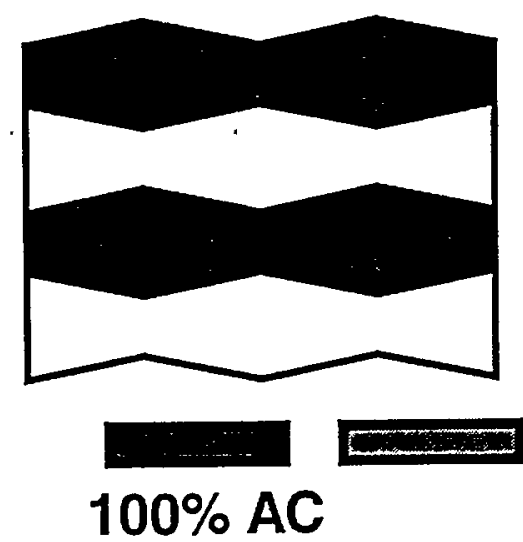

(b)

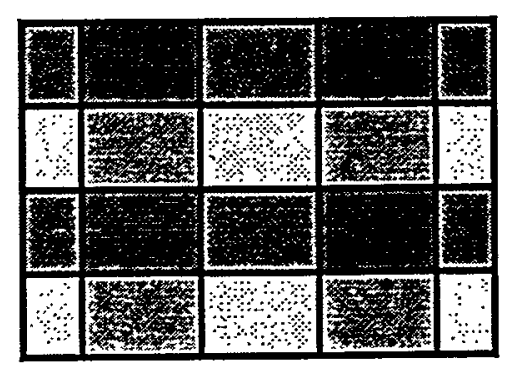

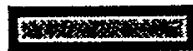

$x+3 x$ (c)

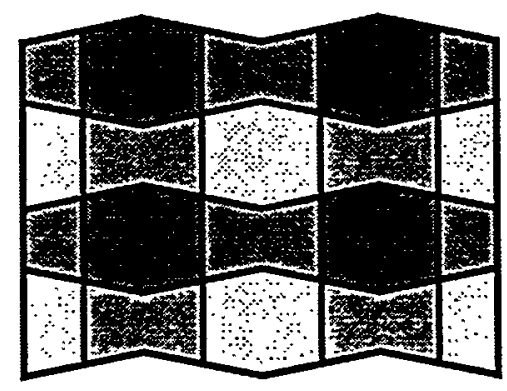

.........

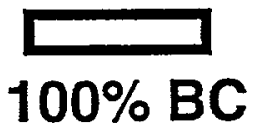

Fig. 1. Diagram illustrating different types of lateral modulations in SLS of compound semiconductors $\mathrm{AC} / \mathrm{BC}$.

(a) Antiphase thickness modulation of pure $\mathrm{AC}$ and $\mathrm{BC}$ layers or $\mathrm{A}$-rich and $\mathrm{B}$-rich layers.

(b) Purely modulation in composition of A-rich and B-rich layers after vertical intermixing.

(c) Coupled modulations in both thickness and composition of A-rich and B-rich layers.

of $(\mathrm{GaP})_{m}(\mathrm{InP})_{n}$ on $\mathrm{GaAs}$ and $(\mathrm{GaAs})_{\mathrm{m}}(\operatorname{InAs})_{\mathrm{n}}$ SPSs on InP substrates, where $\mathrm{m}$ and $\mathrm{n}$ are the number of monolayers (MLs) of the different binary III-V semiconductors in a SPS period. Subsequently Cheng et al. used this in-situ spontaneous lateral superlattice formation process to form the active regions of quantum wire semiconductor lasers $[4,5]$. Kim et al. [6] used this process to form self-organized dot and columnar structures in $(\mathrm{GaP})_{\mathrm{m}}(\operatorname{InP})_{\mathrm{n}}$ SPSs grown on (N11) GaAs substrates. Ponchet et al. [7, 8] reported the formation of thickness modulations in strain-balanced GaInAsP/GaInAsP SLSs grown by gas source MBE and GaInP/InAsP SLSs grown by MOVPE. These morphological instabilities resulted in an antiphase modulation in thickness of the SLS layers (Fig. 1(a)) that in some cases could have been associated with a coupled compositional modulation. The occurrence of this instability led to degraded performance of devices fabricated from such structures. Mirecki-Millunchick et al. $[9,10]$ reported the spontaneous formation of lateral modulations in strain balanced MBE (AlAs) $)_{m}(\operatorname{InAs})_{n}$ SPSs on InP similar to those previously reported by Cheng et al. $[2,3]$ in MBE $(\mathrm{GaP})_{\mathrm{m}}(\mathrm{InP})_{\mathrm{n}}$ and $(\mathrm{GaAs})_{\mathrm{m}}(\mathrm{InAs})_{\mathrm{n}}$ SPSs.

In this work we report recent results that extend the understanding of the nature and origin of spontaneous lateral composition modulations in (AlAs) ${ }_{m}(\mathrm{InAs})_{\mathrm{n}}$ SPSs. We also show that regular unidirectional lateral superlattice structures may be achieved by control of the InAs mole fraction and growth on offcut substrates.

\section{EXPERIMENTAL DETAILS}

The samples examined in this work typically consisted of 100 period (AlAs) ${ }_{m}(\operatorname{InAs})_{n}$ SPSs grown by MBE on top of $100 \mathrm{~nm}$ thick lattice-matched InAlAs buffer layers on (001) InP substrates. The SPS period $(m+n)$ was kept between typically $\approx 2.6$ and 4 MLs. Growth temperatures between 540 and $560^{\circ} \mathrm{C}$ (as measured by an optical absorption technique [11]) and growth rates of $\approx 0.35 \mathrm{MLs}$ per second were normally used. RHEED intensity oscillations were used to calibrate the growth rates. The lateral modulation in the SPS samples was investigated using $\mathrm{x}$-ray diffraction reciprocal space mapping, atomic force microscopy (AFM) (Park Scientific Instruments Autoprobe LS, in air) and transmission electron microscopy (TEM) and diffraction (TED) (Philips CM 30). TEM samples were prepared by conventional mechanical 
pre-thinning and dimpling techniques followed by $\mathrm{Ar}^{+}$ion milling with the sample cooled to liquid $\mathrm{N}_{2}$ temperatures. The chemically sensitive $\{200\}$ reflection was used to reveal the nature of the lateral modulations present in the sample [11-14].

\section{RESULTS AND DISCUSSION}

\section{Effect of Growth Parameters on Modulation Strength and Wavelength}

The lateral modulations were found to be kinetically suppressed for growth temperatures below $520^{\circ} \mathrm{C}$. The modulations became less regular at temperatures above $=565^{\circ} \mathrm{C}$ probably due to effects of In desorption. The optimum growth temperature range was found to be between $\approx 540$ and $560^{\circ} \mathrm{C}$. The strength of the modulations was found to increase with a decrease in growth rate indicating again that kinetics plays an important role in the formation of the modulations $[11,12,14]$. At lower growth rates a reduced vertical alignment of the modulations was also observed. The strength of the modulation was reduced as the period of the SPS was reduced from $4 \mathrm{ML}$ down to $1 \mathrm{ML}[11,12,14]$. For all these experiments the wavelength of the modulations remained remarkably constant between $\approx 20$ and $35 \mathrm{~nm}$. Further details of these experiments are given in the paper by Follstaedt et al. [11].

\section{Effect of Change in InAs Mole Fraction on the Lateral Modulations}

A series of samples was grown to investigate the effect of change in InAs mole fraction $x,(=$ $\mathrm{n} /(\mathrm{n}+\mathrm{m})$ ), on the nature and strength of the lateral modulations. X-ray reciprocal space maps of $(\mathrm{AlAs})_{\mathrm{m}}(\mathrm{InAs})_{\mathrm{n}}$ SPS samples containing lateral modulations taken around the (002) and (224) peaks revealed lateral satellites associated with the modulations [14]. Reciprocal space maps were taken projecting along the orthogonal [110] and [-110] directions. For low InAs mole fraction SPS, between $x \approx 0.43$ and 0.50 , these maps revealed lateral satellites of different spacing along the [110] and [-110] directions [10]. These results indicated that the lateral modulation in these samples is not one dimensional along [110] as suggested for $(\mathrm{GaP})_{m}(\operatorname{InP})_{n}$ and $(\mathrm{GaAs})_{\mathrm{m}}(\operatorname{InAs})_{\mathrm{n}}$ SPSs $[2,3]$ but is probably 2 dimensional (2D) in nature. The relative strength of the lateral composition modulations was determined by measuring the net integrated

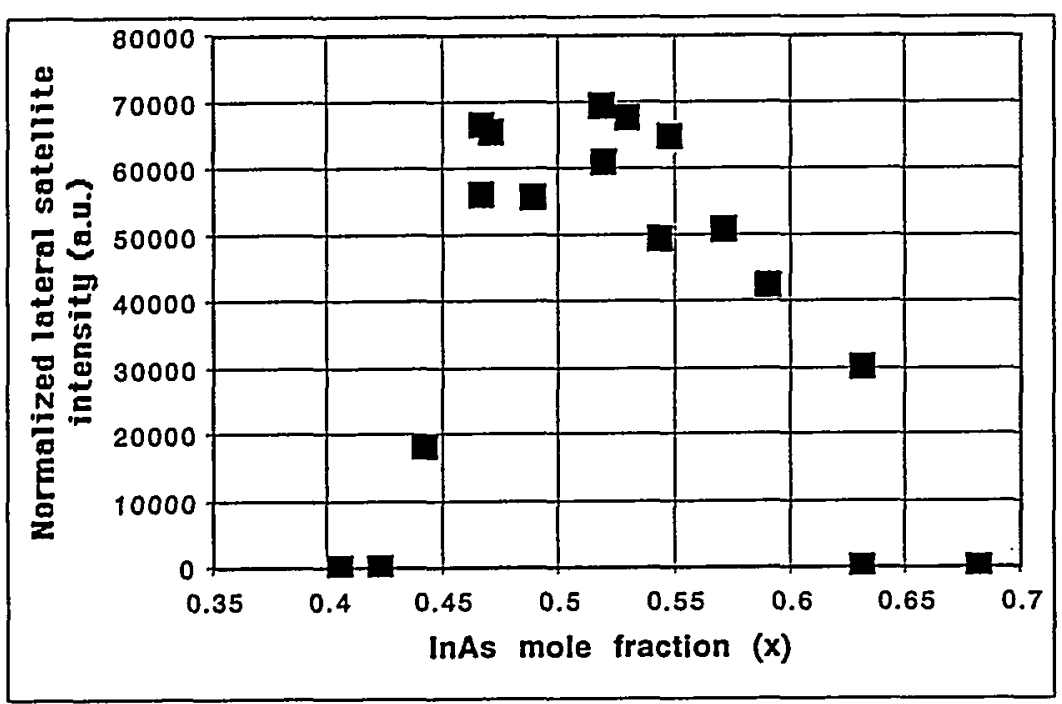

Fig. 2. Plot of normalized lateral satellite intensity versus InAs mole fraction $x=n /(n+m)$. intensity of the lateral satellites in $\mathrm{x}$-ray diffraction reciprocal space maps [14]. These values were then normalized to take into account the fact that the total number of deposited monolayers varied with each sample since the number of SPS periods was kept constant at 100 [14]. Fig. 2 shows a plot of this normalized lateral satellite intensity versus InAs mole fraction $(x)$ for the set of samples mainly studied in this work. The maximum strength of modulations occurred at an InAs mole fraction of $x \approx 0.5^{\circ}$ for which $\mathrm{n}=\mathrm{m}$. This is also 
close to $x \approx 0.52$ where the global strain between the SPS and the InP substrate is zero. For $x>$ 0.52 the SPS is under global compression and for $x<0.52$ the SPS is under global tension. At both high and low InAs mole fractions ( $n>m$, and $n<m$ ), and thus high values of global inplane strain $(>0.7 \%)$, the XRD measurements show that the lateral modulations are suppressed. This behavior is reminiscent of a miscibility gap in alloys. The wavelength of the modulations as measured by $X R D$ remained remarkably constant, between $\approx 20-30 \mathrm{~nm}$, with change in $\mathrm{X}$.

TEM plan-view and cross-section studies and AFM studies were performed to study the effect of changing the InAs mole fraction (x) of the SPSs on the nature of the lateral modulations and planarity of the growth surface. For low values of $x,<0.43$, corresponding to high tensile global strains, no lateral modulations were observed and a very uniform vertical SPS was obtained $[12,13]$. The growth surfaces were observed to be very planar by AFM, with a RMS roughness $\approx 0.4 \mathrm{~nm}$. For $0.43<\mathrm{x}<0.50$ lateral modulations were observed to be present simultaneously along close to the [130] and [310] directions [15], rotated at $\approx \pm 27^{\circ}$ to [110] in the (001) growth plane, as shown in the plan-view TEM picture (sample EA0122) of Fig. 3 (a). This sample had $\mathrm{x}=0.466$ corresponding to a global strain with respect to the substrate of $+0.37 \%$ tension. In this (200) dark field (DF) micrograph In-rich regions appear bright and Alrich regions appear gray, with a null in intensity in between caused by the (200) reflection scattering factor passing through zero at an In mole fraction of $\mathrm{x} \approx 0.52$ [11-13]. Small domains of modulations along the two different $<310>$ directions are visible forming arrays of short stripes perpendicular to the modulation directions. In areas where the two $<310>$ modulations superpose, e.g. circled region, a rhombohedral array of In-rich and Al-rich vertical columns.is formed along the [001] growth direction. Inset is the fast Fourier transform (FFT) of the image which contains two pairs of lobes of intensity rotated $\pm 53^{\circ}$ from [110] that clearly shows the periodic nature of the modulations and their alignment along directions close to [310] and [130]. The wavelength of the modulations was measured to be $\lambda \approx 23-28 \mathrm{~nm}$. The existence of modulations along $<310>$ directions is very surprising since these are not the elastically soft directions ( $<100>$ normally for these materials) nor the direction of bonding at the (001) surface $(<110>$ for these materials) and to our knowledge has not been reported before for other systems.

Fig. 3. (a) $200 \mathrm{DF}$ plan-view TEM of SPS with $\mathrm{x}=0.466(+0.37 \%$ global tension), showing lateral modulations along close to [130] and [310] and (b) AFM image of growth surface showing an identical pattern of grooves on the growth surface. 
AFM studies of the growth surface [15] (Fig. 3(b)) revealed a network of surface grooves or cusps, aligned along $\langle 310\rangle$ directions, which formed an identical pattern to the lateral modulations revealed in the TEM plan-view images. The RMS roughness was measured to be $\approx 1-2 \mathrm{~nm}$. TEM cross-section studies combined with scanning transmission electron microscope (STEM) energy dispersive $\mathrm{x}$-ray microanalysis (EDX) [13] directly revealed a cusping of the growth surface to be associated with narrow In-rich regions in the modulated samples that were separated by wider Al-rich regions. This suggests that the grooves observed in the AFM images of the growth surface of these samples (Fig. 3(b)) correspond to In-rich regions in the modulated samples. For such modulated low $x$-value samples the STEM EDX analysis revealed the composition to vary from $x=0.76$ in the In-rich regions to $x=0.38$ in the Al-rich regions [13].

For samples with high InAs mole fractions, $x>0.63, \mathrm{XRD}$ indicated little or no lateral modulation occurring. AFM studies of such samples revealed the growth surfaces to be very rough and irregular, with a RMS roughness $\approx 6 \mathrm{~nm}$. The difference in roughness between the high tensile and compressive global strain samples is very similar to that reported by Xie et al. [16] for SiGe layers grown under tensile and compressive strain. This was associated by them with a lowering of surface atomic step energy predicted to occur for surfaces under compression in comparison to surfaces under tension promoting enhanced roughening of compressively strained surfaces. TEM studies of $x>0.63$ samples revealed weak composition modulations to be present but to be irregular in both direction and wavelength. For the case of InAs mole fractions between $x \approx 0.52$ and $x \approx 0.63$, lateral composition modulations were found to be present along close to the elastically soft [100] and [010] directions [15], with $\lambda \approx 27-30 \mathrm{~nm}$, as shown in Fig. 4(a). In this sample $(E A 0150) x \approx 0.571$, corresponding to a global strain of $\approx-$ $0.34 \%$ compression, the modulations superpose to give an almost square array of In-rich and Alrich vertical columns, e.g. circled area, along the [001] growth direction. This modulation pattern is very similar to that observed for lateral ordering of vertically stacked InAs quantum dot arrays grown on (001) GaAs, e.g. Solomon [17], Shchukin and Bimberg [18]. The inset FFT contains two pairs of Iobes at an angle of $\approx 83^{\circ}$ corresponding to the lateral modulations present along close to the $<100>$ directions. AFM revealed the lateral modulations are coupled to a surface

Fig. 4. (a) $200 \mathrm{DF}$ plan-view TEM of SPS with $\mathrm{x}=0.571$ (global strain $=-0.34 \%$ compression), showing lateral modulations along close to the elastically soft $\langle 100\rangle$ directions and (b) AFM image of growth surface showing $<100>$ surface rippling: 
Fig. 5. (a) [-110] cross-section 002DF TEM image of lateral modulations in SPS of Fig. 3 with $x=0.466$ (global tension) and (b) [100] cross-section of lateral modulations in Fig. 4 with $\mathrm{x}=0.571$ (global compression).

rippling along close to the $\langle 100>$ directions [14] (Fig. 4(b)) with a RMS roughness of $\approx 1-2 \mathrm{~nm}$.

Fig. 5(a) and (b) shows [-110] and [100] cross-sections of the samples of Figs. 3 and 4 respectively. Vertical columns of In-rich and Al-rich material are visible in both samples. The contrast observed for the compressive sample of Fig. 5(b), however, suggests it contains a more sinusoidal-like composition modulation along the $\langle 100\rangle$ directions. Although in some samples, such as Fig. 5(a), strong modulation seems to occur almost immediately after the start of growth of the SPS in general the modulation starts weak and is amplified during further growth of the SPS as visible in Fig. 5(b). In Fig. 6 is shown a $200 \mathrm{DF}$ plan-view TEM micrograph of a sample (EA0147) grown with very close to zero global strain and $x \approx 0.518$, i.e. at the maximum of the plot of XRD lateral satellite intensity versus $x$ of Fig. 2. Strong lateral modulations are present in this sample but with a less clearly defined directionality in comparison to the tensile and compressive global strain samples of Fig. 3 and 4. This is seen in the inset FFT where the intensity from the modulations is much more spread out in angle around the central peak. AFM of this sample again revealed a surface morphology that closely mirrored the pattern of composition modulations.

Fig. 6. 200DF plan-view TEM of SPS with $x$ $=0.518$ ( $+0.016 \%$ global tension $)$, showing strong lateral modulations but with not well defined modulation direction or pattern.
We have also examined $\mathrm{MBE}$ $(\mathrm{GaAs})_{\mathrm{m}}(\mathrm{InAs})_{\mathrm{n}}$ SPS grown under global tension and compression on (001) InP substrates. In these samples lateral 
modulations were observed along close to the $<310>$ and $<210>$ directions, $\pm 20-27^{\circ}$ from [110], in the tensile samples and $\pm \approx 33^{\circ}$ from [110], along close to $\left.<510\right\rangle$ directions, in the compression sample.

\section{Evolution of the Modulations}

In order to understand how the lateral modulations form we have investigated the evolution of the modulations from the start of growth of the SPS on the lattice-matched InAlAs buffer layer that acts a template for further growth. The InAlAs buffer layer is not necessarily homogenous since several forms of compositional modulation have been observed in MBE InAlAs epitaxial layers [19-21]. In our InAlAs buffer layers a very weak lateral composition modulation was observed, in plan-view TEM studies, along [110] with a wavelength of $\approx 9 \mathrm{~nm}$ similar to that reported previously [20,21] in MBE InAlAs layers grown at lower temperatures. The elastic stresses associated with this compositional modulation could influence the nucleation of the first InAs layer of the SPS [18]. In Fig. 7 (a) and (b) are shown AFM and TEM plan-view micrographs of a $1.9 \mathrm{ML}$ InAs layer.deposited on a lattice-matched InAlAs buffer layer. Due to surface segregation of In that occurs during growth of the InAlAs buffer layer the thickness of this first InAs layer is larger than expected [13]. It can be clearly seen that the InAs layer is not flat but contains islands consisting of quantum 'wires' elongated along [-110] and quantum dot like features. The 'wires' are $\approx 0.5 \mathrm{~nm}$ high, $\approx 50-100 \mathrm{~nm}$ long and $\approx 4-9 \mathrm{~nm}$ wide and their size and shape may have been influenced by the compositional modulation present in the underlying InAlAs buffer layer described above. The dots are $\approx 1-1.5 \mathrm{~nm}$ high. The 'wires' tend to group together and show some lateral ordering along the elastically soft $<100>$ directions. Similar InAs wires have been reported by several workers for MBE growth on (001) InP substrates with either InGaAs or InAlAs buffer layers [22, 23]. These wires and dots in the initial InAs layer of the SPS may play an important role in the initiation of the lateral composition modulations. They are arranged in a pattern with periods of $\approx 18-22 \mathrm{~nm}$ along [110] and $\approx 60-100 \mathrm{~nm}$ along $\langle 100\rangle$.

Fig. 7. (a) AFM image of sample consisting of $1.9 \mathrm{ML}$ of InAs, i.e. 0.5 periods of SPS, on lattice-matched InAlAs buffer layer showing InAs "wires" elongated along [-110] and quantum dot like features. (b) TEM plan-view bright field image of similar sample, using mass/thickness contrast, showing dark contrast InAs "wires" elongated along [-110]. 
The period along [110] is close to that observed for the lateral modulations. The $<100>$ lateral ordering, although longer in period, is along the same directions as the lateral modulations in the compressive samples. Therefore these initial layer island features may act as the precursor to the modulation. However, the initial InAs layer is often identical in thickness in our low and high InAs mole fraction samples and so something else must happen during further growth of the SPSs to give the different patterns of lateral modulations observed for these samples. Cullis et al. [24] observed a similar evolution from [-110] elongated initial growth islands to $\langle 100\rangle$ aligned intersecting surface ripples during the growth of compressive strained InGaAs layers on (001) GaAs. Although InAs islands in the initial layer of the SPS may play a role in nucleating the modulations they are not the only parameter that determines the presence of the modulations. We have grown SPSs at both low $(<0.43)$ and high $(>0.63)$ InAs mole fractions with $n \approx 1.9 \mathrm{ML}$ that do not contain lateral modulations [11] despite InAs quantum wires and dots probably being present in the initial InAs layer of the SPS. This highlights the important influence of InAs mole fraction or global in-plane strain on the occurrence of the modulations.

To investigate the evolution of the different patterns of modulations, from the initial InAs layer grown, in SPSs with $x>0.52$ and $x<0.52$ we grew a series of samples, of both high and low $x$, stopping the growth after 1.5, 2.5, 5.5, 10.5 and 20.5 periods of the SPS. In Fig. 8 (a) and (b) are shown 200 DF TEM plan-view pictures of low and high InAs mole fraction samples respectively after growth of 20.5 periods. For the low $x$ sample, global tension, even after 20.5 periods of the SPS the lateral modulations have not fully developed along the $<310\rangle$ directions. Instead wire like InAs-rich features elongated along [-110] are visible, similar in scale to those observed in Fig. 7, and the inset FFT suggests that modulation is starting to occur along $\langle 310\rangle$. AFM of this sample revealed wire like features elongated along [-110] similar to but less pronounced than those shown in Fig. 7 (a). For the high $x$ sample shown in Fig. 8 (b), global compression, lateral modulations were again not fully developed after 20.5 periods of the SPS. In this sample only very weak wire-like features elongated along [-110] were observed in the TEM. The inset FFT revealed very broad and diffuse lobes of intensity aligned approximately along the

Fig. 8. 200DF plan-view TEM pictures. (a) 20.5 period SPS with $\mathrm{x}<0.5$ showing InAs-rich wire like features elongated along [-110]. FFT suggests $<310>$ modulation may just be starting. (b) 20.5 period SPS with $x>0.5$ showing only weak InAs wire-like features elongated along [-110]. FFT suggests that $<100>$ modulation may have started to occur. 
$<100>$ directions suggesting lateral modulation starting to occur along close to the $<100\rangle$ directions. AFM of this sample was very similar to that of the low InAs mole fraction sample described above.

\section{Origin of the Modulations}

There are many possible origins of lateral modulations during the epitaxial growth of $\mathrm{III}-\mathrm{V}$ semiconductor alloys and strained-layer superlattices. During the growth of alloys, composition modulations may develop for thermodynamic reasons, for example due to phase separation by spinodal decomposition associated with the presence of a miscibility gap e.g. [25, 26]. Also, during growth of alloys, composition modulations may develop due to a kinetic instability as described in detail by Ipatova et al. [27]. During the growth of strained layers, modulations in thickness of the layers may develop due to misfit-strain induced morphological instabilities [28-30]. For the growth of strained alloy layers both kinetic [31] and thermodynamic models [32] indicate that composition modulations can be coupled to the morphological instabilities. Related to this is the strain-induced formation of arrays of 2D and 3D islands, e.g. quantum dots, which can vertically stack in multilayer structures due to interaction with the long range elastic strain fields of previously buried islands e.g. [17, 18, 33-37]. Preferential incorporation of different types of atoms at step edges and step bunching effects can also result in composition modulations in alloy layers and thickness fluctuations in layers [38-40]. The origin of the lateral modulations in the SPS samples described here is probably a combination of several of the above effects. Simple surface phase separation due to the existence of a miscibility gap for the InAlAs alloy is unlikely since the strong lateral modulations observed in the SPSs are not observed in the unstrained lattice-matched InAlAs buffer layer which is grown at the same temperature and has a similar composition to the average composition of the (AlAs) ${ }_{m}(\operatorname{InAs})_{n}$ SPSs: It would thus seem that the driving force for the occurrence of the lateral modulations in the SPSs reported here is the high lattice misfit between the individual SPS layers and the InP substrate. One of the most likely scenarios for the origin of the modulations is therefore associated with stress-induced surface roughening as outlined below. It is well known that a surface subject to stress is unstable towards roughening, e.g. rippling, faceting, step bunching or the formation of arrays of two and three dimensional islands, which can lower the elastic strain energy, e.g. $[7,8,16-18,22-24$, $28-38,41-48]$. Such surface roughening occurring during the growth of an SPS leads to thickness variations in the layers that could give an apparent modulation in composition. Once surface roughening of an alloy layer occurs, preferential incorporation of different sized atoms can happen on the growth surface at sites of different strain states in order to lower the strain energy of the growing layer leading to composition modulations coupled to the surface roughening [31].

Modulations in component layer thickness, possibly coupled to compositional modulation, are commonly observed during the growth of strain-balanced SLSs with lower misfits and longer periods to the structures examined in this work. For example Ponchet et al. $[7,8,41 ; 49]$ reported an antiphase thickness modulation of the component layers in gas source MBE and MOVPE strain balanced GaInAsP/GaInAsP, GaInP/InAsP and GaInAs /InAsP SLSs (Fig. 1(a)). A rapid amplification of the layer thickness modulation was observed and different surface roughness was observed for the layers under tension and compression. The origin of this roughening of the layers is thought to be due to a morphological instability associated with the compressive and tensile misfit of the SLS layers with respect to the substrate. A schematic drawing showing how such antiphase thickness modulations can develop in strain-balanced SLSs is shown in Fig. 9. We assume that the compressive layer is deposited first. Due to a morphological instability this layer will want to roughen to lower the strain energy. For compressively strained layers this 
Fig. 9. Schematic diagram showing possible origin of antiphase thickness modulations in strain-balanced SLSs [7]. Rapid amplification of layer thickness modulation observed.

normally takes the form of surface rippling. along the elastically soft $\langle 100\rangle$ directions as observed for SiGe on $\mathrm{Si}$ and InGaAs on GaAs $[16,24,43]$. The compressive stress is able to relax at the peaks of the rippling and is concentrated at the valley bottoms [29]. Now if we start to grow a layer under tensile strain containing smaller sized atoms on this roughened compressive layer the smaller atoms are likely to be preferentially incorporated into the regions of the valley bottoms on the compressive layer to minimize the strain energy. If enough of the tensile material is deposited it will eventually form a peak at this position as shown. It is still energetically favorable for the smaller atoms of the tensile layer to be deposited in this position at the peak. This is because the tensile stress is relaxed at the positions of the peaks of roughening in the layer under tensile strain [29]. Thus by this process an antiphase thickness modulation of the component layers in the SLS will start to develop. If we now start growing another compressive layer containing larger atoms on top of this structure the larger sized atoms are likely to be preferentially incorporated in the valleys of the tensile layer where the tensile stress is concentrated to lower the strain energy. If enough of this compressive material is deposited it will form a peak in the roughening at this position as shown. The larger atoms will continue to be preferentially incorporated at these positions since the compressive stress is relaxed at peaks in roughened compressively strained layers [29]. Thus this process can rapidly lead to antiphase thickness modulations in strain-balanced SLSs (Fig. 1(a)) as suggested by Ponchet et al [7]. Such antiphase thickness modulations result in apparent lateral composition modulations in the SLS samples (Fig. 1(a)). If the layers in the SLS are alloys then genuine lateral composition modulations coupled to the surface roughening can also develop by preferential incorporation of the different sized atoms at the surface regions of different elastic strain states [31], (Fig. 1(c)).

Is there any evidence that such a surface roughening mechanism is operating in the (AlAs) $)_{m}(\operatorname{InAs})_{\mathrm{n}}$ SPSs investigated in this work? We have so far not directly observed antiphase thickness fluctuations in these samples by cross-sectional TEM but this may be a result of the component layers of the SPS only being $\approx 2 \mathrm{MLs}$ thick and the imaging conditions used. However, the AFM results directly reveal the presence of surface roughening coupled to the lateral modulations. The lattice misfits of AIAs and InAs to InP are $-3.5 \%$ and $+3.2 \%$ respectively. For a morphological instability of a coherently strained layer exhibiting latticemisfit with respect to the substrate, the critical wavelength of surface roughening above which roughening is stable is given by the following expression [28]: 


$$
\lambda_{c}=2 \pi \mathrm{E} \gamma / \varepsilon^{2} \approx \mathrm{K} / \varepsilon^{2}
$$

where $\gamma$ is the surface free energy, $\varepsilon$ is the lattice misfit, and $E$ is Young's modulus of the layer. If for III-V alloys we assume that these quantities remain constant then the expression can be simplified, as above, to $\lambda_{c} \approx K / \varepsilon^{2}$, where $K$ is a constant. We can then take values of $\lambda_{c}$ reported for different values of lattice misfit $\varepsilon$ for individual SLS layers in strain-balanced SLSs in the literature and calculate the value of the constant $\mathrm{K}$. We then use the above expression to predict the wavelength $\lambda_{c}$ expected for the (AlAs) ${ }_{m}$ (InAs) ${ }_{n}$ SPSs assuming an average misfit $\varepsilon$ of \pm 3.35 $\%$ for the individual SPS layers with respect to the InP substrate. The results are shown in Table I. It can be seen that the predicted wavelengths all lie between 25 and $30 \mathrm{~nm}$ which is remarkably close to the experimentally observed wavelengths, between 20 and $35 \mathrm{~nm}$, thus supporting the idea of a stress induced roughening mechanism. Obviously, due to the component layers of the SPSs investigated here being only about $2 \mathrm{MLs}$ thick, such a roughening would probably have to start out as an array of $2 \mathrm{D}$ monolayer high islands or trenches [18, 36, 44-48]. This 2D roughening would then vertically stack in successive periods of the SPS, with some amplification in the roughening occurring, due to the elastic strain field of the already deposited material influencing the incorporation of the arriving atoms at the growing layer surface $[7,17,18,27$, 33-37]. Thus vertical columns of In-rich and Al-rich material would form as experimentally observed in the SPS samples:

Table I. Predicted wavelength of lateral modulations in (AlAs) $)_{m}(\operatorname{InAs})_{n}$ SPSs assuming an average misfit of $\pm 3.35 \%$ between individual SPS layers and InP substrates from previous data using equation 1

\begin{tabular}{|l|l|l|l|l|l|}
\hline Author & Material & Misfit & $\begin{array}{l}\lambda \\
(\mathrm{nm})\end{array}$ & K & $\begin{array}{l}\text { Predicted } \lambda(\mathrm{nm}) \\
\text { for } \varepsilon \approx \pm 3.35 \%\end{array}$ \\
\hline Ponchet et al. [49] & GaInP/InAsP on InP & $\pm 1 \%$ & 280 & 0.028 & 25 \\
\hline Desjardins et al. [50] & GaInP/InAsP on InP & $\pm 0.75 \%$ & 550 & 0.031 & 28 \\
\hline Giannini et al. [51] & GaInAs/GaAsP on GaAs & $\pm 1 \%$ & 330 & 0.033 & 29 \\
\hline
\end{tabular}

The different directions observed for the lateral modulations in samples with high and low InAs mole fraction, $x$, might also be evidence for a surface roughening mechanism. For samples with $x>0.5$ the InAs-rich layers under compression are thicker than the AlAs-rich layers under tension whilst the opposite is true for the samples with $\mathrm{x}<0.5$. Strained layers under compression, e.g. SiGe on $\mathrm{Si}$ and $\mathrm{InGaAs}$ on $\mathrm{GaAs}[16,24,43]$, have been observed to roughen by rippling along the elastically soft $\langle 100\rangle$ directions to lower the strain energy. Assuming a vertical stacking of antiphase thickness modulations occurs in the (AlAs) (InAs) $_{\mathrm{n}}$ SPS samples, as shown in Figs. 9 and 10, then for the samples with $x>0.5$, roughening associated with the thicker compressively strained InAs-rich layers will tend to dominate. This is most likely a rippling or an array of $2 \mathrm{D}$ islands aligned along the $\langle 100\rangle$ directions. This would result in the $<100\rangle$ lateral modulations observed in these samples as shown in Figs. 4 and 5 and schematically in Fig. 10. Layers under tensile strain have been observed to exhibit different forms of surface roughening, e.g. faceting on \{114\}A planes along the [110] direction in InGaAs on InP $[41,42]$. Scanning tunneling microscopy performed by Robach et al. [22] revealed a difference in roughening during the early stages of growth on $\operatorname{InP}$ of $\operatorname{InAs}(\varepsilon=-3.1 \%)$ under compression and $\mathrm{GaAs}(\varepsilon=3.7 \%)$ under tension. The GaAs grown under tension was observed to form anisotropic platelets, mainly $1 \mathrm{ML}$ high, $8-12 \mathrm{~nm}$ wide along [110] and elongated along [-110] right from the earliest stages of growth. Further growth resulted in the anisotropic structures extending and coalescing along [-110] forming interconnected $3 \mathrm{D}$ island chains separated by 3D holes and trenches, very narrow in the [110] direction and elongated along [- 
Fig. 10. Diagram showing how a combination of antiphase thickness modulation and different preferred directions of roughness for compressive and tensile layers can lead to modulations along different directions in SPSs with $x>0.5$ and $x<0.5$.
110]. The formation of such 3D holes or trenches elongated along [-110] during the growth of layers under tension seems to be a more general phenomenon for III-V alloys. It has also been observed for the growth of tensile InGaAs layers on (001) InP [52] and tensile GaAs on (001) InAs [53]. It is possible, therefore, that a similar roughening occurs during the growth of the tensile AlAs layers in the (AlAs) $(\mathrm{InAs})_{\mathrm{n}}$ SPSs samples investigated here, but with the trenches or grooves being aligned along the $<310>$ directions. In the (AlAs) $)_{m}(\text { InAs) })_{n}$ SPS samples with $x<0.5$ roughening associated with the thicker AlAs-rich layers under tension would tend to dominate, which in this case seems to be a trenching or grooving along $<310>$ directions, resulting in the lateral modulations along $<310>$
and the global strain $\approx 0$, the InAs directions in these samples (Figs. 3,5 and 10 ). When $x \approx 0.5$ and the global strain $\approx 0$, the InAs
and AlAs layers are very close in thickness and so it would be expected that neither of the patterns of roughness associated with the layers under compression and tension would dominate. This is observed in Fig. 6 for a sample (EA0147) where XRD measurements indicate $x=0.518$ corresponding to a global strain of $+0.016 \%$ tension with respect to the $\operatorname{InP}$ substrate. For this sample strong composition modulations are present but with a much less well defined directionality than in samples with $x$ further away from 0.5, e.g. Figs. 3 and 4.

The $<100>$ modulation direction in the high InAs mole fraction samples is not unexpected since it is normally the elastically soft direction for these materials. Lateral modulations in phase separated alloys, surface rippling in compressively strained layers and lateral ordering of vertically stacked quantum dots are observed along the $<100\rangle$ directions e.g. $[16-18,24,26$, $34-37,43]$. The $<310>$ directions of the lateral modulations in the low InAs mole fraction samples is very unusual and would not be expected for a bulk effect unless high values of tensile stress changed the elastically soft direction of these materials to along $\langle 310\rangle$. However, $<310\rangle$ directionality is observed at the (001) surface of semiconductors. For example it has been reported that InAs quantum dots grown on GaAs substrates and lattice-matched InGaAs buffer layers on InP substrates may have a pyramidal shape bounded by $\{136\}$ facets [54-56] which intersect the (001) surface along the [3-10] and [1-30] directions perpendicular to the modulation directions in the low InAs mole fraction (AlAs) ${ }_{\mathrm{m}}(\mathrm{InAs})_{\mathrm{n}}$ SPS samples. Step bunches have also been observed to spontaneously form along $\langle 310\rangle$ and $<210\rangle$ directions of the (001) surface of $\mathrm{GaAs}$ during annealing suggesting low energy facets form along these directions [57]. During the initial stages of $\mathrm{Si}$ and $\mathrm{Ge}$ growth by MBE on (001) $\mathrm{Si}$ and $\mathrm{Ge}$ rows of dimers have been observed by STM to form along <310> directions [58-60]. These examples all suggest that the $<310>$ direction of modulations is a result of a surface roughening mechanism such as faceting, 
step bunching, or a preferred shape of $2 \mathrm{D}$ or $3 \mathrm{D}$ islands or trenches occurring probably on the AlAs layer surfaces which are under tension. For example if InAs quantum dots bounded by $\{136\}$ facets with $<310>$ edges [54-56] form in the first InAs layer of the SPS deposited these may encourage formation of $<310>$ lateral modulations during subsequent growth of the low InAs mole fraction SPSs.

The finding that the lateral modulation strength decreases with reducing the SPS period below 4ML [11] also supports that a stress-induced surface roughening process may be causing the modulations. This is because any effects of roughening will be reduced for thinner layers. The suppression of lateral modulations at both very high and low InAs mole fractions, behavior reminiscent of a miscibility gap in alloys, is not however easy to explain by the surface roughening mechanism proposed above. If antiphase thickness modulation of the component layers of the SPS occurs as shown in Figs. 1(a), 9 and 10 then it may be expected that the maximum amplitude of apparent composition modulations should occur when the thickness of the component layers is equal, i.e. $x=0.5$. For $x>0.5$ or $x<0.5$ one of the component layers becomes thinner than the other and this may lead to a reduction in the amplitude of the apparent composition modulations. At high values of global strain of the SPS with respect to the substrate, corresponding to high and low values of $\mathrm{x}$, stress-induced surface roughening or smoothing associated with the high global strain may play an important role. A RMS surface roughening of $\approx 1-2 \mathrm{~nm}$ was measured by AFM for samples with. $0.45<\mathrm{x}<0.6$ that contained strong lateral modulations. For a sample with $\mathrm{x}=0.63(-0.707 \%$ global compression) that contained no modulations as judged from XRD the SPS surface became very rough, with a RMS roughening of $6 \mathrm{~nm}$. Conversely for a sample with $\mathrm{x}=0.422(0.673 \%$ global tension) that contained no modulations the SPS surface became very flat, with a RMS roughness of $\approx 0.4 \mathrm{~nm}$. The observed surface roughening behavior at high global strains is similar to that reported previously for SiGe layers grown under compression and tension [16] and discussed previously in this manuscript. The roughening or smoothing associated with high values of the global strain of the SPS at high and low $\mathrm{x}$ may dominate or inhibit the thickness modulations of the component layers of the SPS and hence suppress the formation of regular lateral modulations. Alternatively, the suppression of modulations at high and low $\mathrm{x}$ may reflect the existence of a genuine miscibility gap in the SPS alloy system.

Engineering of Unidirectional Lateral Superlattices or Quantum Wires by Control of InAs Mole Fraction and Substrate Offcut

The (AlAs) $)_{m}(\mathrm{InAs})_{n}$ SPS samples grown on exactly (001) orientation substrates contain lateral modulations simultaneously present along two directions in the (001) growth plane [15]. These are the orthogonal $<100\rangle$ directions at $\pm 45^{\circ}$ from [110] for high $\mathrm{x}$ samples and $\langle 310\rangle$ directions at $\pm 27^{\circ}$ from [110] for low $x$ samples. These modulations along the two different directions in (001) orientation samples can superpose to form a dense 2D array of In-rich and Alrich [001]-oriented vertical columns (15) which may be of interest for some device applications (6). However for other potential device structures lateral modulations are required such that they form lateral superlattices or arrays of quantum wires along a single crystallographic direction in the growth plane. AFM studies of SPS samples grown on (001) substrates revealed a single modulation direction may be preferentially selected at the edges of surface pits, as shown in Fig. 11. This observation motivated a study of both high and low InAs mole fraction (AlAs) $(\mathrm{InAs})_{\mathrm{n}}$ SPS samples on (001) substrates offcut $2^{\circ}$ towards (111)A, (111)B and (100), the most commonly available offcuts, to investigate if a single modulation direction could be controllably obtained. There are several reasons why growth on offcut substrates could select out a single modulation direction. Firstly the offcut will impose step flow growth to occur along the offcut 
Fig. 11. AFM image of SPS with $x=0.442$. Showing preferential selection of [130] and [310] modulation directions at opposite sides of surface pit. direction which could distinguish between the development of the lateral modulations along the different directions if the offcut direction makes different angles to the modulation directions. Secondly the offcut will introduce an extra anisotropy in surface diffusion due to the presence of step edge diffusion barriers which may select between the two modulation directions. The offcut will also introduce an anisotropy in the surface step density that may select between the modulation directions if bunching of surface steps plays an important role in surface roughening and modulation formation. Also the offcut will influence the initial nucleation of InAs islands in the first SPS layer grown, e.g. preferential nucleation of islands at the step edges, which may influence the modulation development. All of these effects will be enhanced when the two directions of modulation lie at different angles to the offcut direction and the step edges. The maximum effect may therefore be expected for high InAs mole fraction SPSs grown on (001) substrates offcut towards (100) since one modulation direction lies close to parallel to the offcut direction whilst the other lies close to perpendicular to the offcut direction. This selection behavior is observed to occur in such a sample as shown in Fig. 12 where a unidirectional modulation is present parallel to the [100] offcut direction forming.wires $\approx 14-16 \mathrm{~nm}$ wide and up to $1 \mu \mathrm{m}$ long running parallel to the step edges on the offcut surface. The modulation wavelength, $\approx 28-33 \mathrm{~nm}$, is similar to that observed for growth on exactly (001) substrates and is over three times longer than the terrace width of $8.4 \mathrm{~nm}$ expected for a $2^{\circ}$ offcut substrate (if no step bunching occurs) suggesting it is not controlled by the offcut angle. Preferential selection of

Fig. 12. (a) 200 DF TEM plan-view image of SPS with $x=0.583$ grown on (001) InP substrate offcut $2^{\circ}$ towards [100] showing compositional modulation along only the [100] direction. (b) AFM image of growth surface of the same SPS sample showing the presence of "wires" up to $1 \mu \mathrm{m}$ long. 
a single $<310>$ modulation direction can also be obtained for low InAs mole fraction SPSs grown on (001) substrates offcut towards (100), see Follstaedt et al. [11] this proceedings.

\section{CONCLUSIONS}

Strong lateral composition modulations are formed during the MBE growth of $(\mathrm{AlAs})_{\mathrm{m}}(\mathrm{InAs})_{\mathrm{n}}$ SPS's at temperatures between $\approx 540$ and $560^{\circ} \mathrm{C}$. The strongest modulations are observed for samples with InAs mole fractions $\approx 0.5$ and when $\mathrm{n}$ and $\mathrm{m} \approx 2$ MLs. The modulations are suppressed for both very low and high InAs mole fractions. At InAs mole fractions $>0.52$ (global compression) the modulations lie along close to the elastically soft $<100>$ directions, whilst at InAs mole fractions $<0.52$ (global tension) the modulations lie along $<310>$ directions at $\pm 27^{\circ}$ to [110]. The modulations may be a result of surface roughening as a consequence of morphological instabilities associated with the high lattice misfit between the individual SPS layers and the InP substrate. We have demonstrated that by controlling the InAs mole fraction and choosing the correct substrate offcut a single modulation direction can be obtained which is very promising for some future device applications.

\section{ACKNOWLEDGEMENTS}

The authors would like to acknowledge the U.S. Dept. of Energy for funding this work. NREL is a national laboratory operated by the Midwest Research Institute, Battelle, and Bechtel, for the U.S. Dept. of Energy under contract DE-AC36-99GO10337. Sandia is a multiprogram laboratory operated by Sandia Corporation, a Lockheed Martin Company, for the U.S. Dept. of Energy under contract DE-AC04-94A $\$ 5000$.

\section{REFERENCES}

1. A.E. Blakeslee, A. Kibbler, and M.W. Wanless, Superlattices and Microstructures 1, p. 339 (1985).

2. K.C. Hsieh, J.N. Baillargeon, and K.Y. Cheng, Appl. Phys. Lett. 57, p. 2244 (1990).

3. K.Y. Cheng, K.C. Hsieh, and J.N. Baillargeon, Appl. Phys. Lett. 60, p. 2892 (1992).

4. P.J. Pearah, A.C. Chen, A.M. Moy, K.C. Hsieh, and K.Y. Cheng, IEEE J. of Quantum Electron. 30, p. 608 (1994).

5. S.T. Chou, K.Y. Cheng, L.J. Chou, and K.Y. Hsieh, Appl. Phys. Lett. 66, p. 2220 (1995).

6. S.-J. Kim, H. Asahi, M. Takemoto, K. Asami, M. Takeuchi, and S. Gonda, J. J. Appl. Phys. 35, p. 4225 (1996).

7. A. Ponchet, A. Rocher, J.-Y. Emery, C. Starck, and L. Goldstein, J. Appl. Phys. 74, p. 3778 (1993).

8. A. Ponchet, A. Rocher, A. Ougazzaden, and A. Mircea, J. Appl. Phys. 75, p. 7881 (1994).

9. J. Mirecki Millunchick, R.D. Twesten, D.M. Follstaedt, S.R. Lee, E.D. Jones, Y. Zhang, S.P. Ahrenkiel, and A. Mascarenhas, Appl. Phys. Lett. 70, p. 1402 (1997).

10. J. Mirecki Millunchick, R.D. Twesten, S.R. Lee, D.M. Follstaedt, E.D. Jones, S.P. Ahrenkiel, Y. Zhang, H.M. Cheong, and A. Mascarenhas, MRS Bull. 22, p. 38 (1997).

11. D.M. Follstaedt, S.R. Lee, J.L. Reno, R.D. Twesten, A.G. Norman, S.P. Ahrenkiel, H.R. Moutinho, J. Mirecki Millunchick, A Mascarenhas, and E.D. Jones, this proceedings.

12. S.P. Ahrenkiel, A.G. Norman, M.M. Al-Jassim, A. Mascarenhas, J. Mirecki Millunchick, R.D. Twesten, S.R. Lee, D.M. Follstaedt, and E.D. Jones, J. Appl. Phys. 84, p. 6088 (1998).

13. R.D. Twesten, D.M. Follstaedt, S.R. Lee, E.D. Jones, J.L. Reno, J. Mirecki Millunchick, A.G. Norman, S.P. Ahrenkiel, and A. Mascarenhas, Phys. Rev. B 60, p. 13619 (1999). 
14. S.R. Lee, J. Mirecki Millunchick, R.D. Twesten, D.M. Follstaedt, J.L. Reno, S:P. Ahrenkiel, and A.G. Norman, J. Mater. Sci.: Mater. in Electron. 10, p. 191 (1999).

15. A.G. Norman, S.P. Ahrenkiel, H. Moutinho, M.M. Al-Jassim, A. Mascarenhas, J. MireckiMillunchick, S.R. Lee, R.D. Twesten, D.M. Follstaedt, J.L. Reno, and E.D. Jones, Appl. Phys. Lett. 73, p. 1844 (1998).

16. Y.H. Xie, G.H. Gilmer, C. Roland, P.J. Silverman, S.K. Buratto, J.Y. Cheng, E.A. Fitzgerald, A.R. Kortan, S. Schuppler, M.A. Marcus, and P.H. Citrin, Phys. Rev. Lett. 73, p. 3006 (1994).

17. Solomon G.S., J. Electron. Mater. 28, p. 392 (1999).

18. V.A. Shchukin and D. Bimberg, Review of Modern Physics 71, p. 1125 (1999)

19. F. Peiro, A. Cornet, and J.R. Morante, Inst. Phys. Conf. Ser. No. 146, p. 385 (1995).

20. E. Bearzi, T. Benyattou, C. Bru-Chevallier, G. Guillot, J.C. Harmond, O. Marty, and M. Pitaval in Optoelectronic Materials: Ordering, Composition Modulation, and Self-Assembled Structures, edited by E.D. Jones, A. Mascarenhas, and P. Petroff (Mater. Res. Soc. Proc. 417, Pittsburgh PA 1996), p. 271-275.

21. G. Grenet, M. Gendry, M. Oustric, L. Porte, G. Hollinger, O. Marty, M. Pitaval, and C. Priester, Appl. Surface. Sci. 123/124, p. 324 (1998).

22. Y. Robach, M. Phaner, A. Solère, M. Gendry, and L. Porte, Appl. Phys. A 66, p. S1031 (1998).

23. H. Li, J. Wu, Z. Wang, and T. Daniels-Race, Appl. Phys. Lett. 75, p. 1173 (1999).

24. A.G. Cullis, A.J. Pidduck, and M.T. Emeny, J. Crystal Growth 158, p. 15 (1996).

25. F. Glas, J. Appl. Phys. 62, p. 3201 (1987).

26. I.P. Ipatova, V.G. Malyshkin, and V.A. Shchukin, J. Appl. Phys. 74, p. 719.8 (1993).

27. I.P. Ipatova, V.G. Malyshkin, A.A. Maradudin, V.A. Shchukin, and R.F. Wallis, Phys. Rev. B 57, p. 12968, (1998).

28. R.J. Asaro and W.A. Tiller, Met. Trans. A 3, p. 1789 (1972), M. A. Grinfel'd Sov. Phys. Dokl. 31, p. 831 (1986), D.J. Srolovitz, Acta. Met. 27, p. 621 (1989).

29. H. Gao, J. Mech. Phys. Solids 39, p. 443 (1991).

30. B. J. Spencer, P.W. Voorhees, and S.H. Davis, J. Appl. Phys. 73, p. 4955 (1993).

31. J.E. Guyer and P.W. Voorhees, Phys. Rev. Lett. 74, p. 4031 (1995), Phys. Rev. B 54, p. 11710 (1996).

32. F. Glas, Phys. Rev. B 55, p. 11277 (1997).

33. L. Goldstein, F. Glas, J.Y. Marzin, M.N. Charasse, and G. Le Roux, Appl. Phys. Lett. 47, p. 1099 (1985).

34. Q. Xie, A. Madhukar, P. Chen, and N.P. Kobayashi, Phys. Rev. Lett. 75, p. 2542 (1995).

35. J. Tersoff, C. Teichert, and M. Lagally, Phys. Rev. Lett. 76, p. 1675 (1996).

36. V.A. Shchukin, D. Bimberg, V.G. Malyshkin, and N.N. Ledentsov, Phys. Rev. B 57, p. 12262 (1998).

37. V. Hol'y, G. Springholz, M. Pinczolits, and G. Bauer, Phys. Rev. Lett. 83, p. 356 (1999).

38. J. Tersoff, Y.H. Phang, Z. Zhang, and M. Lagally, Phys. Rev. Lett. 75, p. 2730 (1995).

39. J. Tersoff, Phys. Rev. Lett. 77, p. 2017 (1996).

40. A.-L. Barabasi, Appl. Phys. Lett. 70, p. 764 (1997).

41. A. Ponchet, A. Le Corre, A. Godefroy, S. Salaun, and A. Poudoulec, J. Crystal Growth 153, p. 71 (1995).

42. T. Okada, G.C. Weatherly, and D.W. McComb, J. Appl. Phys. 81, p. 2185 (1997).

43. A.G. Cullis, MRS Bull. 21, p. 21 (1996).

44. V. I. Marchenko, JETP Lett. 33, p. 381 (1981).

45. O. L. Alerhand, D. Vanderbilt, R.D. Meade, and J.D. Joannopoulos, Phys. Rev. Lett. 61, p. 1973 (1988). 
46. K.-O. Ng and D. Vanderbilt, Phys. Rev. B 52, p. 2177 (1995).

47. P.D. Wang, N. N. Ledentsov, C.M. Sotomayor Torres, P.S. Kop'ev, and V. M. Ustinov, Appl. Phys. Lett. 64, p. 1526 (1994).

48. G. M. Guryanov, G.E. Cirlin, A.O. Golubok, S.Ya. Tipissev, N.N. Ledentsov, V.A. Shchukin, M. Grundmann, D. Bimberg, and Zh.I. Alferov, Surface Science 352-354, p. 646 (1996).

49. A. Ponchet, A. Rocher, A. Ougazzaden, and A, Mircea, Inst. Phys. Conf. Ser. No. 146, p. 199 (1995).

50. P. Desjardins, H. Marchand, L. Isnard, and R.A. Masut, J. Appl. Phys. 81, p. 3501 (1997).

51. C. Giannini, L. Tapfer, Y. Zhuang, L. De Caro, T. Marschner, and W, Stolz, Phys. Rev. B 55, p. 5276 (1997).

52. P. Krapf, Y. Robach, M. Gendry, and L. Porte, Phys. Rev. B 55, p. R10229 (1997).

53. J.G. Belk, C.F. McConville, J.L. Sudijono, T.S. Jones, and B.A.Joyce, Suface Science 387, p. 213 (1997).

54. H. Lee, R. Lowe-Ẇebb, W. Yang, and P.C. Sercel, Appl. Phys. Lett. 72, p. 812 (1998).

55. H. Saito, K. Nishi, and S. Sugou, Appl. Phys. Lett. 74, p. 1224 (1999).

56. S. Yoon, Y. Moon, T.-W. Lee, H. Hwang, E. Yoon, and Y.D. Kim, Thin Solid Films 357, p. 81 (1999).

57. K. Hata, T. Ikoma, K. Hirakawa, T. Okano, A. Kawazu, T. Ueda, and M. Akiyama, J. Appl. Phys. 76, p. 5601 (1994).

58. J. van Wingerden, A. van Dam, M.J. Haye, P.M.L.O. Scholte, and F. Tuistra, Phys. Rev. B 55, p. 4723 (1997).

59. W. Wulfhekel, B.J. Hattink, H.J.W. Zandvliet, G. Rosenfeld, and B. Poelsema, Phys. Rev. Lett. 79, p. 2494 (1997).

60. X.R. Quin and M.G. Lagally, Science 278, p. 1444 (1997). 

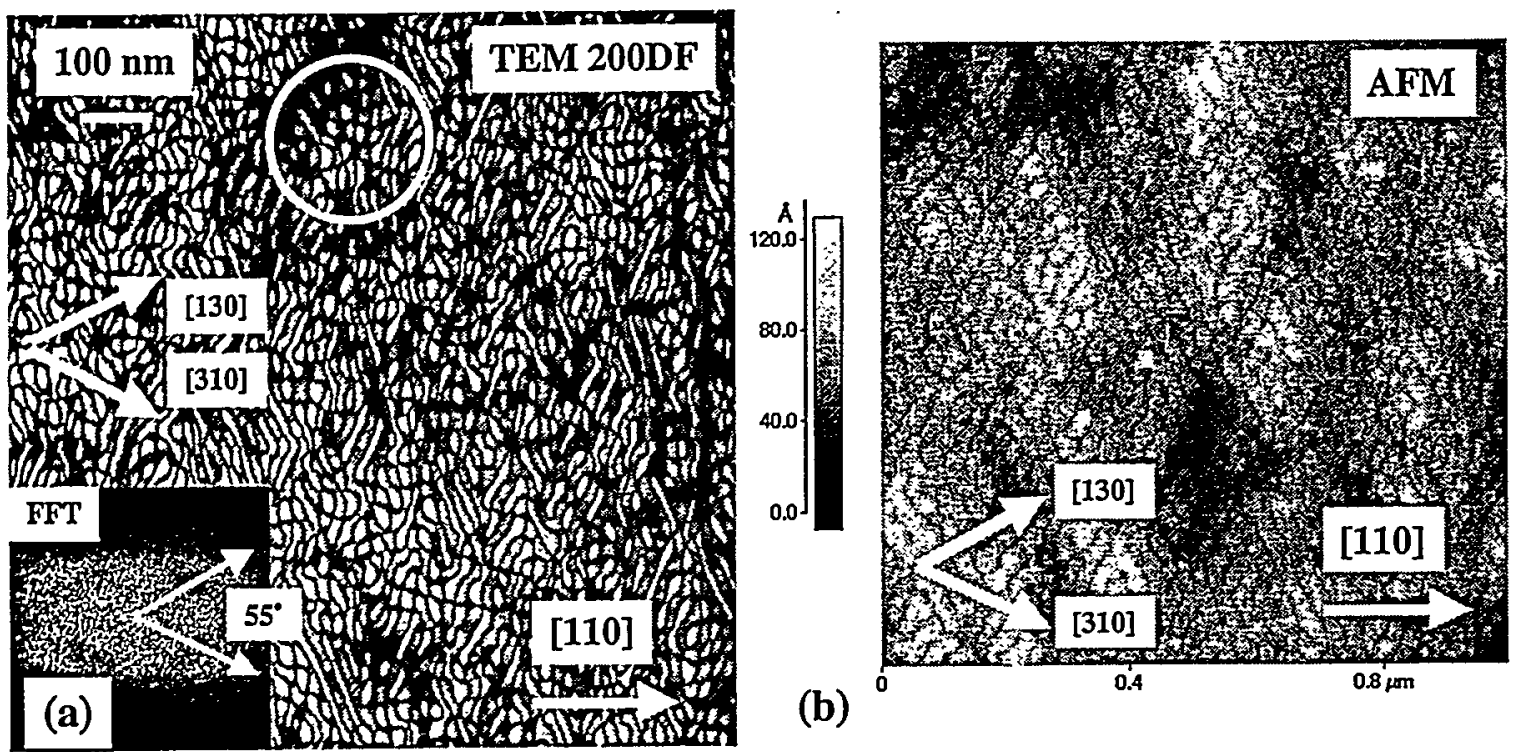

Fig. 3. (a) 200DF plan-view TEM of SPS with $x=0.466$ ( $+0.37 \%$ global tension), showing lateral modulations along close to [130] and [310] and (b) AFM image of growth surface showing an identical pattern of grooves on the growth surface.
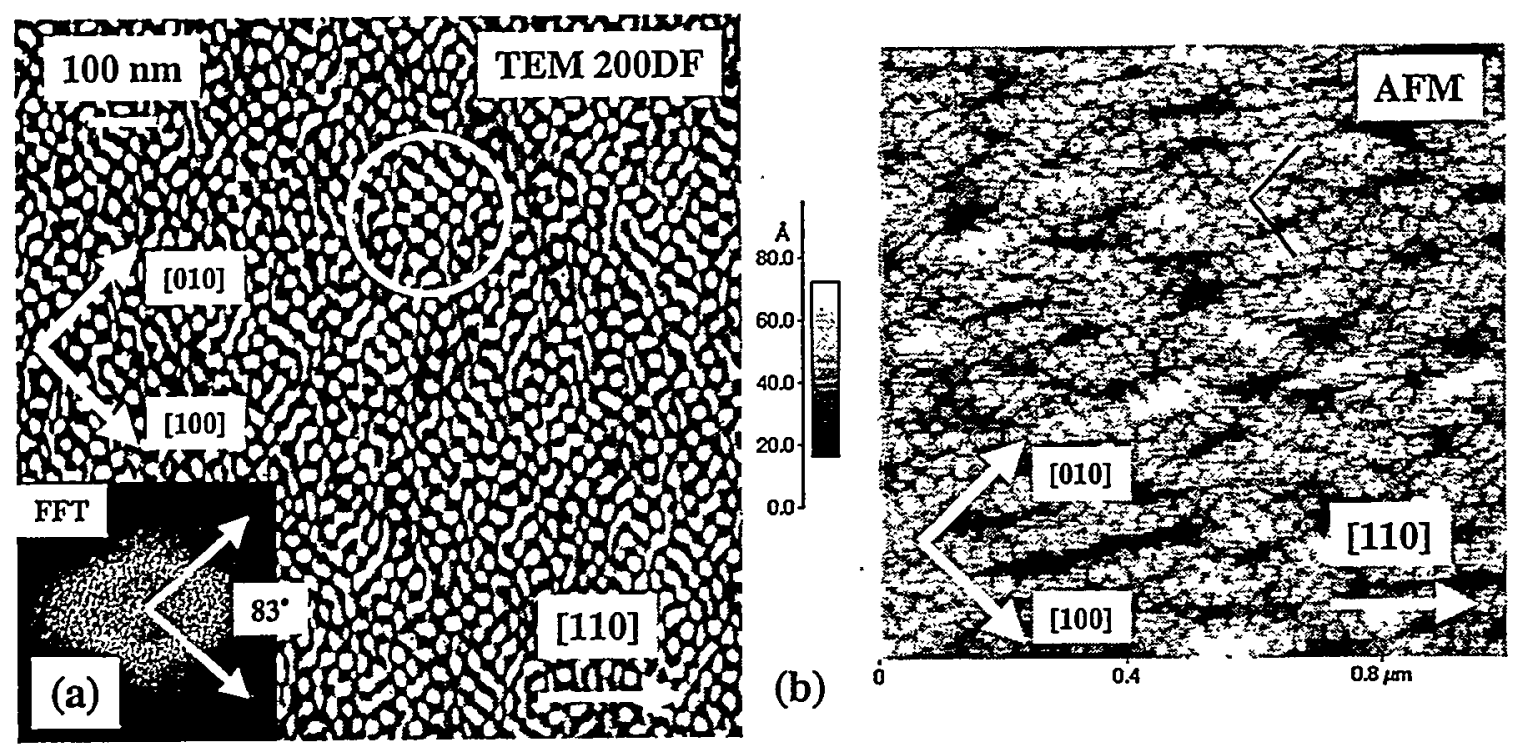

Fig. 4. (a) 200DF plan-view TEM of SPS with $\mathrm{x}=0.571$ (global strain $=-0.34 \%$ compression), showing lateral modulations along close to the elastically soft $\langle 100\rangle$ directions and (b) AFM image of growth surface showing $<100>$ surface rippling. 

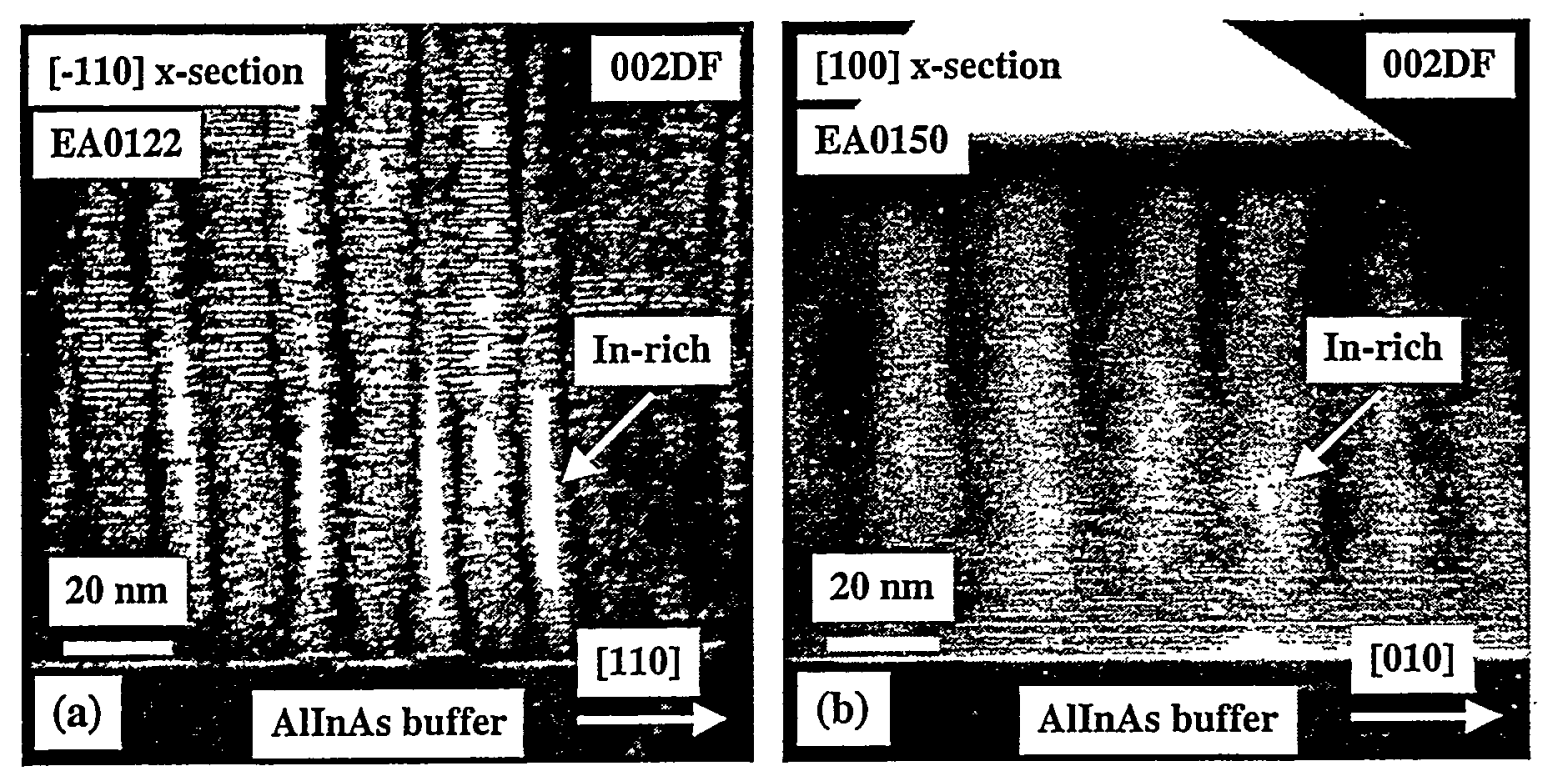

Fig. 5. (a) [-110] cross-section 002DF TEM image of lateral modulations in SPS of Fig. 3 with $x=0.466$ (global tension) and (b) [100] cross-section of lateral modulations in Fig. 4 with $x=0.571$ (global compression).



Fig. 6. 200DF plan-view TEM of SPS with $\mathrm{x}=0.518$ $(+0.016 \%$ global tension), showing strong lateral modulations but with not well defined modulation direction or pattern. 



Fig. 7. (a) AFM image of sample consisting of $1.9 \mathrm{ML}$ of InAs, i.e. 0.5 periods of SPS, on lattice-matched InAlAs buffer showing InAs "wires" elongated along [-110] and quantum dot like features. (b) TEM plan-view bright field (BF) image of similar sample, using mass/thickness contrast, showing dark contrast InAs "wires" elongated along $[-110]$.
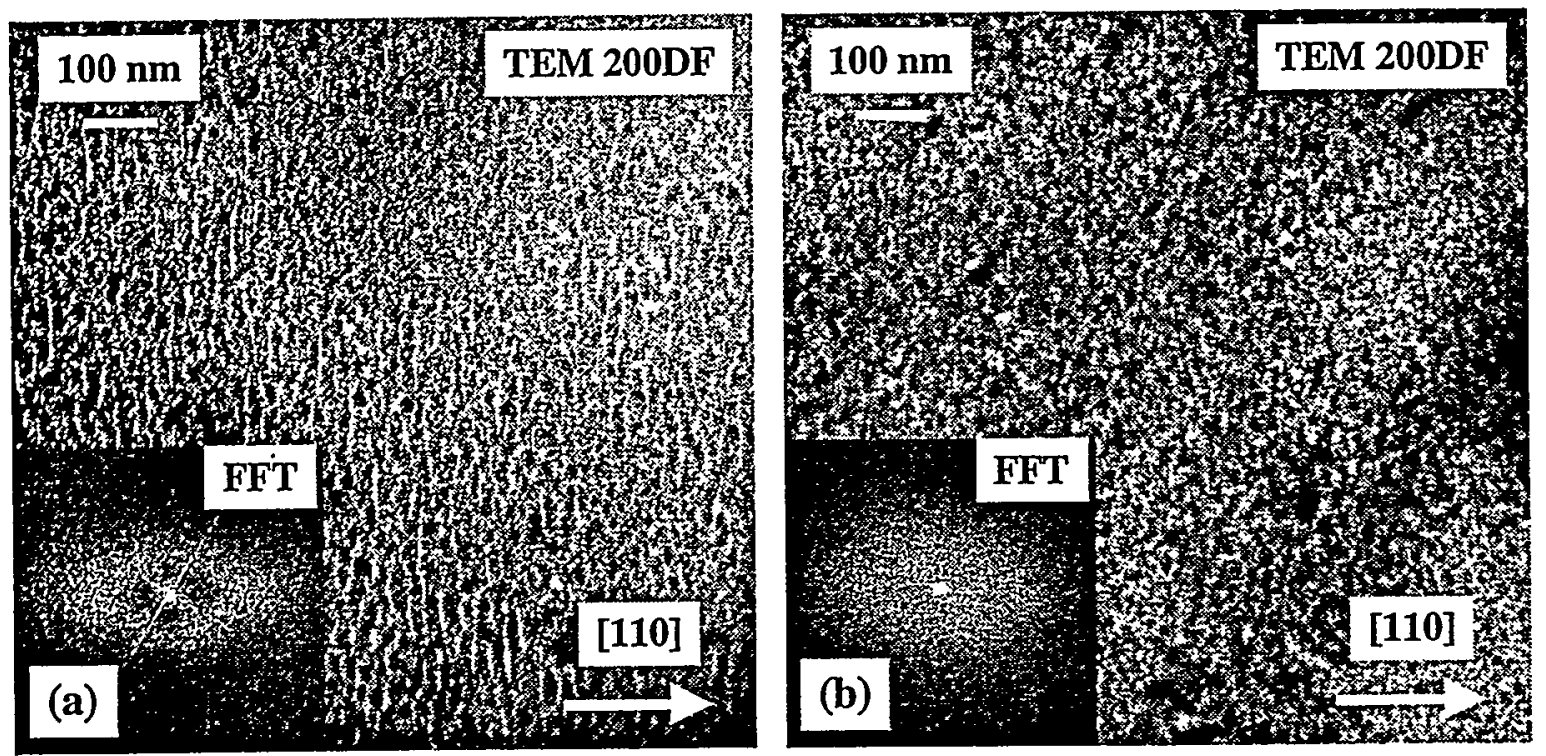

Fig. 8. 200DF plan-view TEM pictures. (a) 20.5 period SPS with $\mathrm{x}<0.5$ showing InAs-rich wire-like features elongated along [-110]. FFT indicates $<310>$ modulation may just be starting. (b) 20.5 period SPS with $x>0.5$ showing only weak InAs wirelike features elongated along $[-110]$. FFT suggests that $\langle 100\rangle$ modulation may have started to occur. 




Fig. 9. Schematic diagram showing possible origin of antiphase thickness modulations in strain-balanced SLSs [7]. Rapid amplification of layer thickness modulation observed.
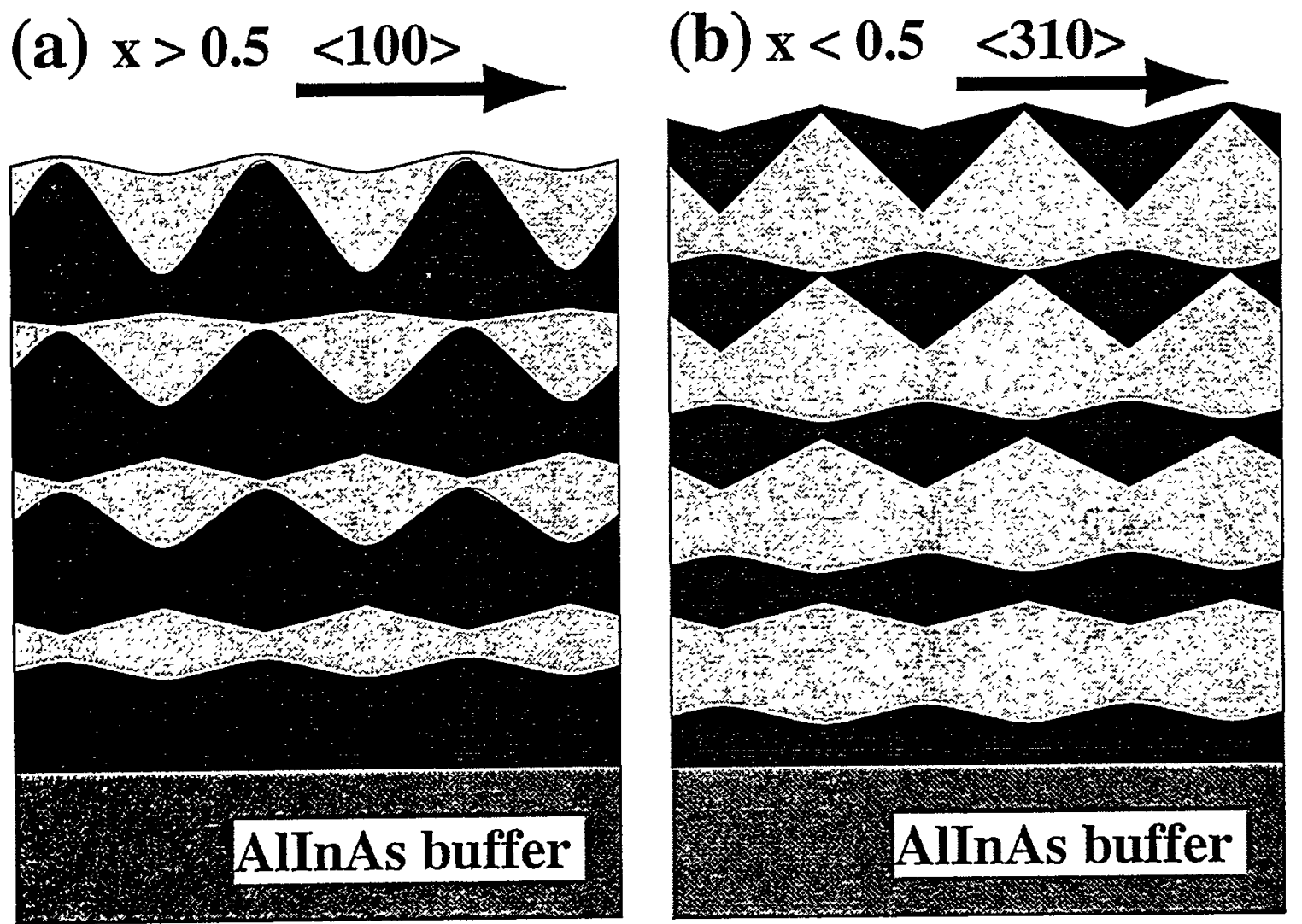

\section{In-rich, compression}

\section{Al-rich, tension}

Fig. 10. Diagram showing how a combination of antiphase thickness modulation and different preferred directions of roughness for compressive and tensile layers can lead to modulations along different directions in SPSs with $x>0.5$ and $x<0.5$. 

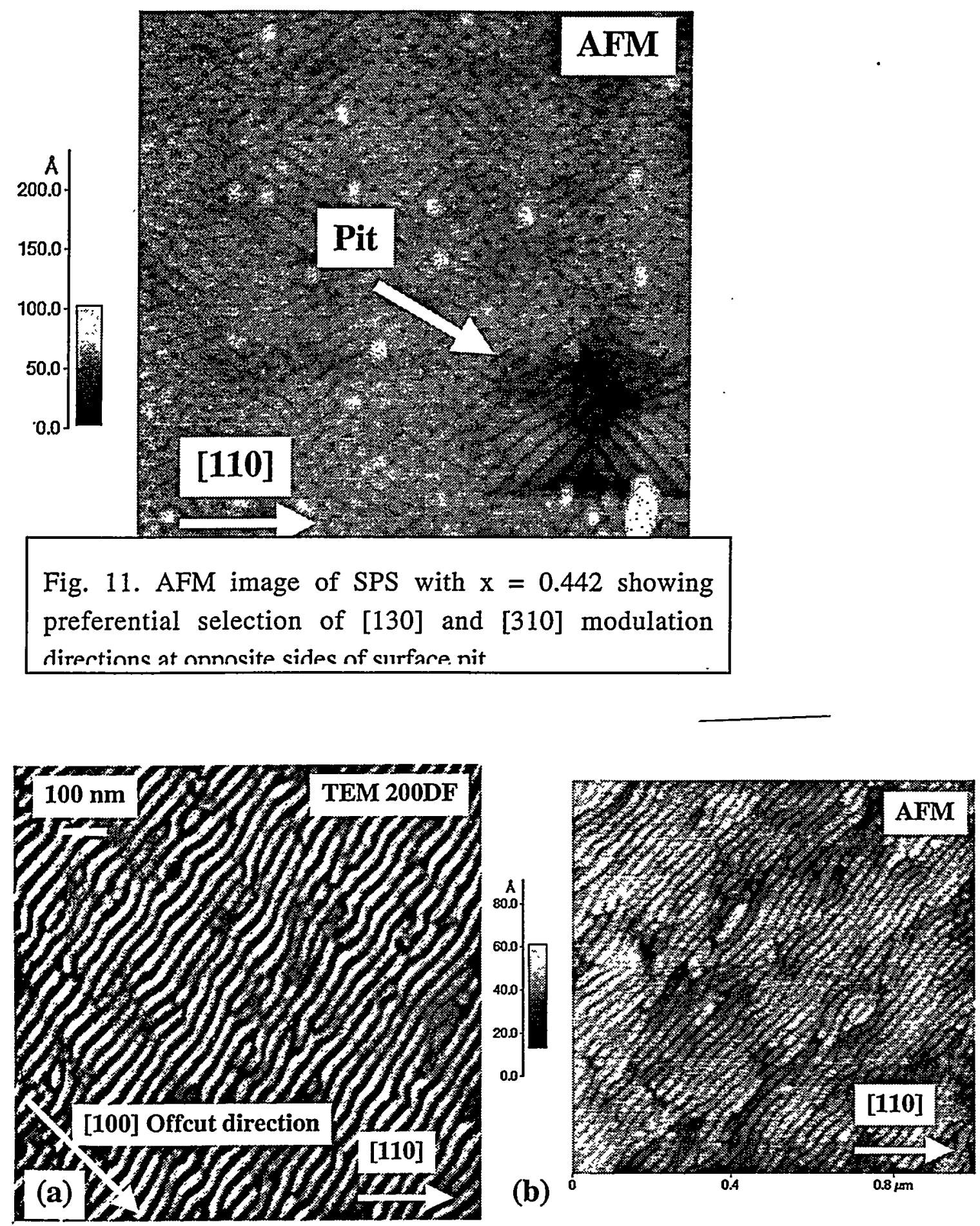

Fig. 12. (a) 200DF TEM plan-view image of SPS with $\mathrm{x}=0.583$ grown on (001) InP substrate offcut 2 towards [100] showing compositional modulation along only the [100] direction. (b) AFM image of growth surface of the same SPS sample showing the presence of "wires" up to $1 \mu \mathrm{m}$ long. 